\title{
Two sides of the one coin:
}

\section{Assessment of students who have previously failed a placement and the role of the practice teacher}

\section{Ruth Murray ${ }^{1}$ and Marguerita McGovern ${ }^{2}$}

Abstract: Why does a student fail? What will be the student's learning needs in any repeat placement? How does the student reflect on their previous placement experience? Can the Practice Teacher provide the appropriate learning experience and facilitate the student to attain the competencies needed to pass a repeat placement? So many questions for all of those concerned with the reality of a failed and repeat placement.

This paper emanates from a presentation by both authors at the Glasgow Conference on Practice Teaching and Field Education in Health and Social Work in April 2014. It will examine the processes of social work placement failure and the task involved in finding a repeat placement for the student. Interesting topics for discussion include: What prompts Practice Teachers to take students who have previously failed? What preparations and conversations take place previous to the student started the repeat placement? How important is the involvement of the student's Tutor in the planning of this next placement? A small sample of practice teachers' experiences who offered placements to students (who had previously failed a placement) will be explored, as will conversations with students who had themselves previously failed. The conclusions attained by the authors both of whom are University Fieldwork Coordinators in researching this topic will be presented, with some interesting results.

Keywords: practice teaching; fieldwork coordinators; supervision; social work competencies; placement

1. , Fieldwork Co-ordinator, School of Applied Social Studies, University College Cork, Ireland

2. Practice Learning Coordinator, School of Political Science and Sociology, National University of Ireland Galway. Ireland

Address for correspondence: r.murray@ucc.ie.

marguerita.mcgovern@nuigalway.ie 


\section{Introduction}

... 'Ever tried. Ever failed. No matter. Try again. Fail again. Fail better'.

Samuel Beckett.

It is encouraging that Samuel Beckett was not a social work student. In the realm of failing on a social work placement, the objective is, having failed, to learn, process and move on to a position of success or if not, be offered an exit route. Failing can be a traumatic event in the professional development of not only the social work student but also the practice teacher and additional stakeholders such as the Tutor and the Fieldwork Coordinator. This article written from the presentation given at the $10^{\text {th }}$ International Conference on Practice Teaching and Field Education in Health and Social Work Conference in Glasgow June 2014, by two Irish Fieldwork Coordinators, one from University College Cork and the other from the National University of Ireland, Galway, looks at the student who has failed and gone on to pass their additional placement and the consequential elements captured within that process.

The supposition is that everything has to be done to help the student before the position gets to the fail stage. In many cases we have seen what might be termed as the 'faltering' student. A student who hits a crisis or difficultly in part of their placement and either needs additional support for a period of time, for example, an extra Tri-partite meeting or session with their Tutor, further supervisory time or more concentration on reflective practice. In numerous instances this student goes on to complete their placement successfully and learns well from their 'hiccup'. A fail grade is much more serious than this; it is not acceptable if it 'comes out of thin air' or has not been flagged sufficiently beforehand. Every effort and help must have been offered to the student who is having difficulties. Communication between the placement, the Tutor and the University is essential (Bucknell, 2000; Durkin and Shergill, 2000; Furness and Gilligan, 2004)

At the National University of Ireland, Galway, a placement can be termed; complete, incomplete or failed. Occasionally, a placement has to finish early due to extenuating circumstances outside of a 'fail' situation. This is deemed to be an incomplete placement. A placement is normally deemed incomplete due to personal circumstances or as a result of difficulties arising in a placement that cannot be reasonably resolved within the placement context. If a placement is deemed incomplete, clear

58 J. of Practice Teaching \& Learning 13(2-3), pp.57-71. @ w\&b 
reasons for the decision must be recorded following a meeting between the placement personnel and the course director. Again it is determined that the placement is not a 'fail'. The student is normally involved in this meeting unless there are exceptional circumstances that deem this inappropriate or unfeasible. The student may continue with their academic studies for that relevant year. Where a placement is signed off as incomplete, a student is then given another opportunity to commence a new placement normally within the next cycle of the module. Furthermore the practice teacher must provide a report signed by the student, to cover the period of the placement and reasons for it being deemed incomplete. The scope of the report will be dependent on the time spent on placement. Going forward, it is expected that normally the new practice teacher will have access to this report as part of the introduction of a new placement.

With the 'faltering' and incomplete placement defined, attention is now focused on the fail predicament. A fail may occur at any point during the life of the placement. If a student is deemed at risk of failing, the practice teacher must alert the tutor and the practice learning coordinator as early as possible to this risk. This will trigger a special/early second tripartite where progress can be reviewed. While at the mid-point, there is an opportunity to confirm whether there is a likelihood of such a fail, given that the Mid Tri- partite form includes the question 'Is there the possibility of the student failing this placement?' It is also possible that concerns around failing can arise closer to the end of a placement. A student should always be informed of this and the tutor and practice learning coordinator also should be involved in managing and recording the process that has resulted in the fail. Where a student fails their placement, they are normally entitled to a second opportunity to resit the placement. Where a placement has failed, the practice teacher must provide a Performance Evaluation Report, signed by the student. It is expected that the new practice teacher at the additional placement will have access to this report as part of the organisation of a new repeat placement.

59 J. of Practice Teaching \& Learning 13(2-3), pp.57-71. @ w\&b 


\section{Assessment frameworks}

At the National University of Ireland, Galway, twenty Masters in Social Work students take on a two year full time professional course. They have one fourteen week placement in each year in a variety of professional agencies. Each student has one practice teacher. In a limited number of placements there are two practice teachers supervising the student. Assessment on placement is a Pass or Fail grade. The practice teacher supervises the student while on placement and writes a Performance Evaluation Report at the end of placement which covers the six professional domains set out by the Government licencing body The Health and Social Care Professionals Council, otherwise known as CORU. The student's assessment is achieved by writing a Portfolio, evidencing their learning on placement.

\section{Why do students fail?}

Social work students on placement can fail for a multifarious number of reasons. Recognition of the general fail grade tends to include; not being able to take direction; lack of commitment; mental health issues; elongated absences; personality problems. One of the more serious areas is 'Fitness to Practice'. The majority of Universities now have a 'Fitness to Practice' Committee where codes of conduct and ethical positions are set out. The professional associations and registration bodies in social work may also have their own Fitness to Practice documents. Either way this is good resource material. Social work students on placement, who fail, need to know why they fail. A direct quote from one student who had failed her first Masters in Social Work placement said 'I came out of the placement not knowing what was wrong. I wasn't given enough feedback to go away and work on the areas. So I was a bit confused. I needed proper feedback. Areas to work on would have helped me get over the fail. I hadn't been given enough flags or preparation for a fail grade'.

60 J. of Practice Teaching \& Learning 13(2-3), pp.57-71. @ w\&b 


\section{How to recognise a student in distress}

Sharp and Danbury's sub title of Activities and Exercises to Prepare Practice Teachers for Work with Failing Students (1999) leads the reader into some aspects of preparedness. But first of all, how might a practice teacher recognise a student who is in danger of failing their placement or one who is in distress? The common sources of student distress include transition difficulties, depression, self-esteem and confidence issues, relationship problems, family/childcare anxieties, financial or welfare concerns, cultural problems and possible loss, grief and attachment life situations. On placement many students attest to feelings of 'being overwhelmed', feeling 'out of control' and 'not knowing what to say'. They may have background issues of feeling tired, not able to concentrate, confused about what is expected of them, gender issues. The student may present as shy, nervous, embarrassed, self-conscious. They may have headaches, feel sick, faint, be dizzy, hot or hyperventilate. Students feeling under acute pressure have problems articulating their thoughts, can stutter or are self-conscious. They might become upset easily. The student who failed her first MSW placement quoted earlier recalled 'I saw the whole thing as traumatic at the time. I felt I'd let myself down and everyone else'. Students having difficulties may have repeated requests for assistance but support from the practice teacher seldom leads to change. On the reverse side, some students show their anxiety by being over confident, loud and may at times resort to 'bully-boy' tactics. A failing student is unable to work on cases with a clear, concise plan and pattern of intervention. Their communication skills are disruptive, their progress cumbersome. Supervision is laboured. The following diagram offers some suggestions regarding further thought on the issue.

The most important question around the failing student is 'Where is the risk?' This takes in many other parties into the equation. The possible risk to clients or service users, to the practice teacher, the Agency, the University personnel and most importantly to the student themselves must be taken seriously.

61 J. of Practice Teaching \& Learning 13(2-3), pp.57-71. @ w\&-b 


\section{Identifying Difficulties}

Is the student's behavior causing concern?

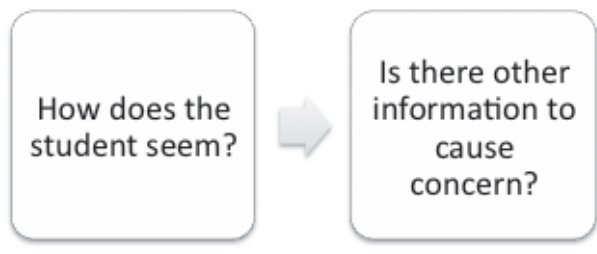

Is this different from your previous experiences of this student?

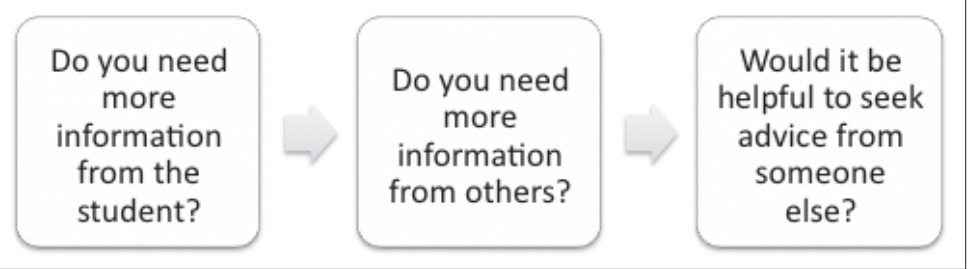

Fig 1. How to recognise a student in distress

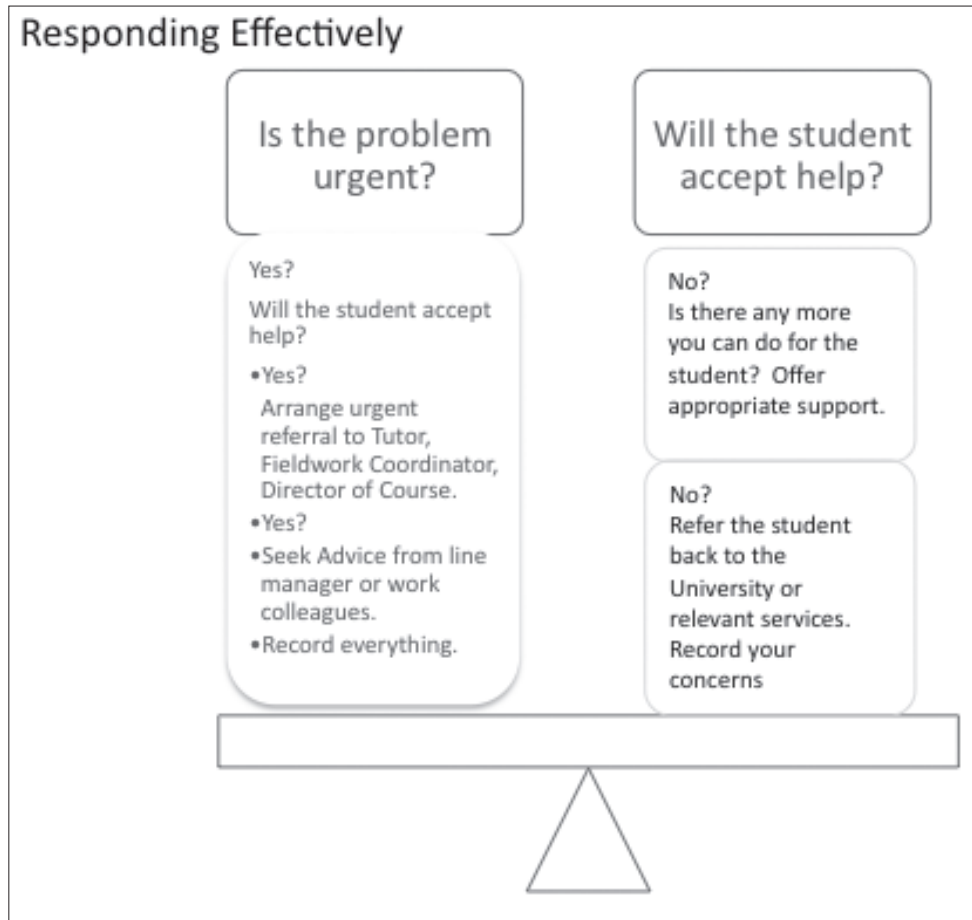

Fig 2. What to do?

62 J. of Practice Teaching \& Learning 13(2-3), pp.57-71. ( ) wEb 


\section{Teaching Practice Teachers on aspects of failed placements}

'Evidence. Evidence. Evidence'. This word repeated for effect is indeed the main mantra of the message from the University to the Practice Teacher. In fairness it is not only important from the University's perspective but if the student is going to fail then they need to know exactly why. They also need to know how and what will happen next. Like all good problem solving techniques, the skill begins with investigation. The continuum goes from initially asking the student to adopt an investigative approach into why they are finding certain aspects of the placement difficult, to a more thorough investigative and evidential approach by the Practice Teacher as the placement draws to its conclusion. Becoming 'task orientated' for Practice Teachers can be at times difficult as it may not be their usual holistic way of working. However, task and outcome can be measured. This will in turn lead to a more direct and succinct discussion and end of placement report. Supervision is important. This is a safe space. Practice Teachers' own experience of supervision is also important to recognise. The degree of influence this will have on the prevailing situation is unclear but it is important to consider. Additionally the influence of power balances and imbalances within the placement and with the practice teacher - student relationship is an important consideration (Harris, 1997). In failing placements the way forward is to identify the difficulties by naming the issues.

Be direct and honest. Move forward any pre-arranged placement meetings. The Tutor is a vital link in the education of the student on placement. They may be a calming influence on heated exchanges and a support for the student who feels threatened. University Fieldwork Co-ordinators and Programme Directors need to be kept informed of progress or decline in all difficult placement situations. In coping with failed placements the overall necessity is reports, reports, reports. Keep accurate and explicit reports of all supervision sessions and meetings. These should be agreed on by all parties and where no agreement is forthcoming notes should be made to these points. The emotional aspect of being involved in a failed placement for the Practice Teacher is not without its own journey. Interviewing a practice teacher who was involved in having to fail a second year MSW student she shared these thoughts, 'It's a very difficult and emotional time to look at a student and say 'I can't

63 J. of Practice Teaching \& Learning 13(2-3), pp.57-71. @ w\&b 
pass you'. It feels like an oppressive practice and not something we're very comfortable doing but we do have to look at our responsibilities as Practice teachers to produce students who are fit for purpose and at best, meet the needs of their service users and clients. To do this the student needs to have attained a certain standard. So while we might feel very sad and conflicted a lot of the time, it's also a dilemma that can cause a lot of sleepless nights. I think you have to be able to step back and make a judgement like we do in our daily work, every day. We may feel sad and guilty that the decision we make may affect this person's career but we have to look at the long term.' She goes on to say, 'One of the most important things for a practice teacher to remember is to maintain positive regard for the student during a difficult placement and to maintain positivity and encouragement for the student regardless of the outcome'.

\section{The responsibility of the university}

In Finch and Taylor's 2013 paper 'Failure to Fail? Practice Educators' Emotional Experiences of Assessing Failing Social Work Students' they suggest 'Universities must develop robust processes to manage situations where there are concerns about practice education which might lead to students being passed who are not yet competent'. It is important for practice teachers to be given the confidence by the pre-placement teaching to fail placements. The worst possible scenario is where the first placement practice teacher on a two year Masters in Social Work course, passes the student and then says 'I wanted to give him/her the benefit of the doubt' or 'They're not great but the next practice teacher might be able to do a better job'. Pre-placement training for practice teachers is vital, as it is for students going out on placement. Expectations across the two groups have to be discussed, managed and a concise direction for learning written within the Fieldwork Manual.

Can anything be done at the admissions point with regard to social work student selection? Only little evidence is available (Holmstrom and Taylor, 2008). We select the best students using rigorous criteria for our University courses. We send students out with the expectation to pass placement. It must be remembered that it is the exceptional student who fails.

64 J. of Practice Teaching \& Learning 13(2-3), pp.57-71. @ w\&b 
Can we learn from other disciplines? There may be interesting research from the medical field (Langlois and Thach, 2000) but in general social work courses would appear to have robust directions around failure on placement which we could indeed share with other disciplines.

\section{The repeat placement for the student}

All students who fail a placement are entitled to a repeat placement. It falls on the Fieldwork Coordinator, along with discussions with the student's Tutor, to find the next placement for the student. The student can be quite apprehensive about this next placement. Self-esteem and confidence are usually low and he/she may be very nervous about what the context of this next placement will be, along with concerns about performance and ability to pass this next placement. This is perfectly understandable. The placement may also be happening out of term time, so the student is concerned about who will know in the next agency that this is a repeat placement, and what information Practice Teacher may be sharing with staff and colleagues about the student.

For the purposes of the presentation of the paper at the Glasgow Conference in 2014, one of the Fieldwork Coordinators from University College Cork, interviewed a number of practice teachers (nine) who had taken repeat students on placement. The Fieldwork Coordinator thought that most practice teachers would be very apprehensive at this next placement and concerned at 'what if the student fails this placement also?' However what came to light was a commitment from the practice teachers to the social work profession, a willingness to offer an opportunity to a student to try again and an overwhelming feeling that they could help the student, based on reading the previous placement report and then meeting with the student. It was indeed 'Two Sides of the One Coin' and not two different coins! All practice teachers felt that reading the previous report, that included the student's learning needs, could be attained now in this placement and the actual meeting of the student pre placement, were all factors in influencing them to offer the student a repeat placement. Serious consideration was also given to how the student might attain his or her learning needs on the repeat placement.

65 J. of Practice Teaching \& Learning 13(2-3), pp.57-71. @ w\&b 
At the start of the additional placement, the research found that all practice teachers acknowledged the following:

1. At the pre placement meeting the student was very nervous.

2. The student was accepting of the fail and the practice teacher and student had some conversation about this at the pre placement meeting.

3. A number of students had reflected on their past situation students before coming to this placement, for example, meeting with someone to gain help with improving writing skills, diary and time management, counselling for themselves, or whatever the student had learnt about himself/herself in relation to the failed placement that it was felt needed to be worked on, and some students took a year out to do this..

4. All students were anxious at the outset of the placement. This dissipated as the weeks progressed.

The Fieldwork Coordinator had anticipated that the practice teachers would be worried about failing a student again. This was not reciprocated by the Practice Teachers interviewed. Rather they all said their focus was on the conversation with the Universities, both with Tutor and Fieldwork Coordinator, prior to making any decision about taking this student. When they then agreed to thinking about taking a repeat student, the previous placement report was then posted to them. On reading this, their next thoughts were: "what are the student's learning needs in this report and can I provide them at this agency?' When it was felt that this could be achieved, all the social workers admitted to talking to either their team leader or principal, in order to ensure that if they did agree to take the student that support was there in the agency for them as the social work student supervisor. All chose within the agency to share with as few people as possible that the student coming had failed the previous placement. However some did add that if the student wished to say it at some stage in the agency while on placement, that would be the student's own choice to do so.

Practice teachers also acknowledged that even though the student had previously failed a placement, the student was also bringing to this placement a whole previous placement experience. So working with this student meant that, despite nervousness and anxiety in

66 J. of Practice Teaching \& Learning 13(2-3), pp.57-71. @ w\&b 
the early weeks, some knowledge and experience was coming with them, be it in child protection, probation or various other service agencies. Students also had rarely failed all six competencies, as outlined by the Government licencing body, The Health and Social Care Professionals Council, otherwise known as CORU. Practice teachers were guided towards, based on the previous placement report, what needed to be worked on by the student.

One practice teacher talked about the importance of assessing the motivation of the student to do social work at the pre placement meeting. If she felt the student was very motivated to still want to practice as a social worker in the future, then the practice teacher felt, as she put it, that she would 'give it a go'. She also said, as did others, that unless she felt the student 'owned' what was in the previous report, then she would more than likely not have proceeded to supervise the student. The practice teacher interviewed said, on saying she would take a student again who had previously failed a placement, said that there is extensive learning for her as practice teacher in proceeding with this placement. There is immense satisfaction in watching a student gain in confidence, particularly one who has 'come to your work place a little bit battered'.

All practice teachers who took the repeat student had previously supervised students before. None therefore were supervising for the first time. This would have been an essential element in panning for the student by the Fieldwork Coordinator. All Practice Teachers said that while they themselves were nervous initially in taking the repeat student, having all the information before taking the student, from the College, helped allay any concerns they might have had. All recalled that they had also almost made the decision to take the student before meeting the student, based on the conversations with the student's Tutor and the College and the reading of the report. On the subject of the previous placement report, one practice teacher phoned, with permission, the previous practice teacher. He said he really regretted this, which was interesting. He felt the previous practice teacher was still back at the negative experience the placement had been for her, and should he be asked in the future to take a student who had previously failed, he would not do so again.

Reading would have been offered in advance by the Fieldwork Coordinator to all practice Teachers in this situation. In particular,

67 J. of Practice Teaching \& Learning 13(2-3), pp.57-71. @ w\&b 
a useful research article 'Gate-keeping for professional social work practice' (Lafrance, Gray and Herbert, 2004) can be of particular benefit to the practice teachers.

All practice teachers said they thought a good deal about offering an additional placement at the outset, probably more than they would normally when supervising a student. They also said that while they all valued regular supervision in any placement, they were extra attentive to making sure that this happened every week and also 'checked in' informally more often with the student than they might do usually, particularly in the early weeks of the placement. The practice teachers all said the early weeks of the repeat placement took more of their time than normal. This was because there was extensive confidence building needed for the student in those early weeks and a nervousness that was apparent in them that needing extra help. All the students surmounted this in time, and in fact some practice teachers kept in touch with their students afterwards, and were delighted to report that they had got paid employment in social work subsequently. For those interviewed who took a repeat student once only, all said that they would consider doing it again if asked (which was very pleasing for the Fieldwork Coordinator to hear).

In brief, if a social worker is considering taking a repeat student, the following check list may provide some helpful pointers:

1. Have you had a conversation with Tutor and Fieldwork Coordinator from the University?

2. Have you read the previous the report carefully?

3. Can this Agency provide the Student's learning needs as identified in the report?

4. Have you the support of at least one other member of staff if you take this on?

5. When meeting the student, what has he/she to say about the previous placement?

6. Have you a sense that the student is ready to move on now from the previous placement experience, and has he/she done any work on themselves to help them be ready for this placement, if that had been a recommendation in the previous report?

All the practice teachers (eight in all) interviewed did not labour or discuss the fail or the previous report again once the student embarked

68 J. of Practice Teaching \& Learning 13(2-3), pp.57-71. @ w\&b 
on the this placement. They all had a positive experience, even if unexpectedly so. All the practice teachers reminded themselves that the student came with social work experience already, having been on a placement before, and that it was important to acknowledge this. Despite this, the student's confidence was at low ebb on arrival into placement. A significant amount of time was spent supporting the student who may be 'emotionally shattered' by having previously failed.

Taking into account where a student was at the start, meant it had taken time to build up confidence and getting students in to a place where they could operate normally in practice. However all were clear that the student's progress was observed throughout the whole placement and a decision to pass the student on this placement was not reached until nearer the end of the placement. All concluded that no matter how well this repeat placement was going, all decisions on the pass/fail grade would not be decided until late or indeed at the very end of the placement.

Interviewing the practice teachers who had supervised students on repeat placements was a positive experience for the Fieldwork Coordinator. There was a positivity about all the practice teachers interviewed, and about their commitment to the social work profession and their responsibility to the practice of teaching social work students.

\section{Recommended best practice}

- Call it early when student is faltering

- Maintain positive regard throughout

- Recognise that this may be highly emotional for all parties

- PTs should avail of supports available to them

- Remember the Tutor and know the University's policies

- Have courage to be the Gatekeeper for the Profession

- Paramount is the Protection of the Service Users

69 J. of Practice Teaching \& Learning 13(2-3), pp.57-71. @ w\&b 


\section{In Conclusion}

It must be remembered that students are assigned to placement agencies on the basis of the student's learning needs and the agencies' ability to facilitate students. Students are therefore expected to handle placement in a mature manner, understanding that legitimate and logical concerns may be discussed in a professional way to achieve the best outcome.

Repeat placement practice teachers should be given all reports pertaining to the previous placement and all lines of communication between stakeholders (student, practice teacher, tutor and University), should be open and honest at all times. Fieldwork Coordinators should not be shy in asking practice teachers to take on repeat placements. The limited amount of research within this article where practice teachers were interviewed showed that they could rise to the challenge and enjoy the experience.

\section{Glossary:}

1. The term Fieldwork Co-ordinator and Practice Learning Coordinator are interchangeable. In Ireland these are University based positions.

2. The term placement Practice teaching refers to the teaching given by the Practice Teacher to the student on placement.

3. The term Practice Placement can also be transposed with Practicum or Field Education. Placement is the current term used in Ireland and the UK.

\section{References:}

Barlow, C. and Hall, B.L. (2007) 'What about feelings?'. A study of emotion and tension in social work field education. Social Work Education, 26. 4, $399-413$

Barron, C. (2004) Do we need a second opinion here? Journal of Practice Teaching in Health and Social Work, 5, 2, 22-38

Finch, J. and Taylor, I. (2013) Failure to fail? Practice educators' emotional

70 J. of Practice Teaching \& Learning 13(2-3), pp.57-71. @ wEb 
experiences of assessing failing social work students. Social Work Education, 32, 2, 244-258

Furness, S. and Gilligan, P. (2004) Fit for purpose: Issues from practice placements, practice teaching and the assessment of students practice. Social Work Education, 23, 465-479

Harris, R. (1997) Power., in M. Davies (Ed.), The Blackwell Companion to Social Work. Oxford: Blackwell

Holmstrom, C. and Taylor, I. (2008) Researching admissions: What can we learn about selection of applicants from findings about students in difficulty on a social work programme? Social Work Education, 27, 8, 819-836

Langlois, J. and Thach, S. (2000) Preventing the difficult learning situation. Family Medicine 32, 4, 232-234

Lafrance, J, Gray, E and Herbert, M. (2004 Gatekeeping for professional social work practice. Social Work Education, 23, 3, 25-340

Parker, J. (2010) When things go wrong! Placement disruption and termination: power and student perspectives. British Journal of Social Work, 40, 983-999

Sharp, M. and Danbury, H. (1999) The Management of Failing DipSWStudents: Activities and exercises to prepare practice teachers for work with failing students. Aldershot: Ashgate/Arena 